\title{
Engaging with nature : Nature affords well-being for families and young people in Finland
}

\section{Rantala, Outi}

2020-07-03

Rantala , O \& Puhakka, R 2020 , ' Engaging with nature : Nature affords well-being for families and young people in Finland ' , Children's Geographies , vol. 18 , no. 4 , pp. 490-503 . https://doi.org/10.1080/14733285.2019.1685076

http://hdl.handle.net/10138/320956

https://doi.org/10.1080/14733285.2019.1685076

acceptedVersion

Downloaded from Helda, University of Helsinki institutional repository.

This is an electronic reprint of the original article.

This reprint may differ from the original in pagination and typographic detail.

Please cite the original version. 


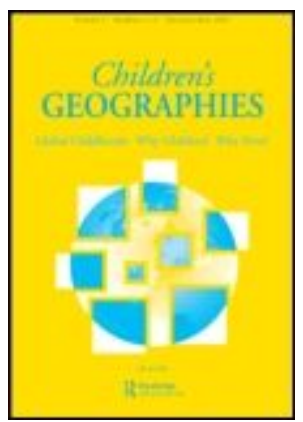

\section{Engaging with nature: nature affords well-being for families and young people in Finland}

\begin{tabular}{|r|l|}
\hline Journal: & Children's Geographies \\
\hline Manuscript ID & Draft \\
\hline Manuscript Type: & Original Article \\
\hline Keywords: & $\begin{array}{l}\text { affordance, well-being, Children, young people, outdoor recreation, } \\
\text { relationality }\end{array}$ \\
\hline
\end{tabular}

\section{SCHOLARONE \\ Manuscripts}




\title{
Engaging with nature: nature affords well-being for families and young people in Finland
}

\begin{abstract}
Contact with nature is increasingly being recognized as contributing to humans' mental and physical health. This study explores how Finnish children, young people and families engage with nature during outdoor recreation. We apply a relational approach with the concept of affordance to understand better how engagement with nature affects their well-being. The study is based on thematic writings of 15-21 year-olds and on an ethnographic study of camping. Findings indicate that engagement with nature enables young people to calm down and to get away from the pressures of everyday life and affords close interaction for families. The relational approach makes visible that the more young people and families spend time in nature, the more they are able to perceive affordances that enhance their well-being. In future research and policy the focus should be on how to support families' engagement with nature by securing time and places for encountering nature.
\end{abstract}

Keywords: affordance; relationality; well-being; children; young people; outdoor recreation

\section{Introduction}

In urbanized societies, natural environments are increasingly valued for the aesthetic experiences they afford, and the public use of areas with a high degree of naturalness has generally changed from one of subsistence to that of recreation (Lindhagen and Hörnsten 2000). The everyday embodied experience of the environment changes when one does not need to work in heating or light, or to deal with waste (Hitchings 2011a). Younger generations' capacities to connect with natural areas in everyday life have diminished, and the general western trend has been a shift away from spontaneous nature-based play towards planned, organized and adult-controlled activities, which often take place in purpose-built facilities (Skar and Krogh 2009). 
At the same time, contact with nature is increasingly being recognized as contributing to our psychological, physiological, and social well-being and health (Kabisch, van den Bosch, and Lafortezza 2017; Keniger et al. 2013). It has been found that spending longer times in nature - especially spending a night in a nature area increases the perceived well-being benefits, in particular psychological well-being (Puhakka, Pitkänen, and Siikamäki 2017). Interacting with nature has been shown to increase self-esteem and mood, reduce anger, and improve general psychological wellbeing with positive effects on emotions and behavior (Kaplan, 2001; Kuo and Sullivan 2001; Maller 2009). Green spaces are restorative and contribute to attentional recovery and reducing mental fatigue (Kaplan 2001). Exposure to nature settings has also positive effects on concentration, academic performance, and the ability to perform mentally challenging tasks (Hartig, Mang, and Evans 1991; van den Berg, Koole, and van der Wulp 2003). Furthermore, performing activities in green areas has been found to alleviate symptoms in children suffering from attention deficit hyperactivity disorder (ADHD) (Kuo and Taylor 2004). In terms of physiological benefits, contact with green space alleviates the negative effects of various stressors in urban environments (Tyrväinen et al. 2014; van den Berg, Koole, and van der Wulp 2003) and encourages people to exercise (Kaczynski and Henderson 2007). Contact with diverse environmental microbiota also affects the human commensal microbiota and drives effective immunoregulation that persists into adulthood (e.g. Hanski et al. 2012).

In terms of social well-being, natural environments and shared nature experiences provide an opportunity for social interaction and strengthening bonds within families and communities. Most beneficial for well-being is interacting with known others, such as family and friends (Dinnie, Brown, and Morris 2013). Compared to an indoor environment, communication between parents and their little children was 
found to be much more responsive and connected in natural environment, in a city centre park, which may constitute optimal environment for communication (CameronFaulkner, Melville, and Gattis, 2018). Nature can also help in personal and community identity formation, social activity and social participation (Keniger et al. 2013; Kuo and Sullivan 2001; Maller 2009). For instance, gardens offer various affordances that catch children's attention easily and make learning social skills effortless for them: manners in which to behave and regard other people, along with the possibilities of building friendships and affections, confidence, and work ethics (Laaksoharju, Rappe, and Kaivola, 2012).

This study contributes to the discussion on how interaction with nature enhances well-being by introducing a relational approach to the interaction. We apply the concept of 'affordance' (Gibson 1979) to analyze how nature as a recreational environment affects well-being among families and youths in Finland. We are interested in the encounters that take place between young people and the recreational environment and families and the recreational environment. Hence, we understand nature and humans as emerging in interaction, and we consider this relational emergence a central feature, which should be better recognized when the interconnections between wellbeing and nature are discussed. The relational approach to the concept of affordance helps to address the emergence analytically.

In a broad sense, well-being is understood to comprise two main elements: feeling good and functioning well (Muirhead 2011; see Dinnie, Brown, and Morris 2013). In this study, well-being is approached inductively, based on the empirical data, and understood very openly. The empirical data consists of thematic writings written by Finnish 15-21-year-olds youth and of an ethnographic data related to Finnish children, young people and families who engage in camping and sleeping outdoors. In Finland, 
cities are still largely embedded in natural environments, and 'everyman's right' gives everyone the basic right to roam freely in the countryside, to camp for a short period as well as to pick berries and mushrooms. In the Finnish National Outdoor Recreation Demand Inventory (LUKE 2010), outdoor recreation refers to all activities which include moving, staying or doing things in natural environment in order to recreate in leisure time. Also spending time at recreational home and tourism, as far as they include these activities, are included in outdoor recreation. In Finland, proximity to a forest and water is an essential element of a summer cottage, and access to a cottage has been found out to increase the rate of participation in outdoor recreation and traditional activities (Sievänen, Pouta, and Neuvonen 2007). On the basis of the national inventory (LUKE 2010), over $96 \%$ of the Finnish population participate in outdoor recreation, the most common activities being walking, biking, and spending time at recreational home. Compared to older age groups, youth favor activities that demand physical skills and/or special equipment (e.g. climbing, mountain biking, downhill skiing) and are motorized (e.g. motor boats, snowmobiles). Many traditional activities, such as hunting, fishing, and cross-country skiing, have lost their importance among youths.

By applying the relational approach to the context of Finnish outdoor recreation, our aim is to bring fore findings that can be taken into account when planning how to enhance engagement with nature among youth and children.

\section{Relational approach to affordances}

James Gibson's concept of affordance is well established in the field of ecological and environmental psychology (Brymer, Davids, and Mallabon 2014). The concept points to the possibilities and restrictions emerging from the environment, which are perceived as functionally meaningful units - for example, as surfaces to be climbed (Gibson 1979; Kyttä 2003). Within the ontology and epistemology of the concept, the immediate 
interaction between the environment and the perceiver is central: it is easier for an individual to perceive affordances than separate qualities of the environment because affordances are meaningful entities (Gibson 1994[1977]). Affordances are seen as being relational and varying, and they depend on situational and physical circumstances as well as individual urges and capabilities (Laaksoharju and Rappe 2017; Rietveld and Kiverstein 2014). Thus, the process of perception is relative to the embodied skills and capacities of the perceiver (Gibson 1994[1977]). Rietveld and Kiverstein (2014) describe this as being attuned towards the material things around us - within the form of life in which we are engaged.

Even though affordances are relative to the skills and capacities, Rietveld and Kiverstein $(2014,337,343)$ suggest that affordances are not relative to the abilities of a particular individual who perceive or detects the affordance, but that the affordances have an existence that is relative to the skills available in a specific sociocultural practice - that is, affordances are relative to the abilities available in a form of life as a whole. Furthermore, they suggest that we should not limit engagement with affordances to specific set of motor skills, but instead we should recognize that the variety of affordances available to us humans is as rich and varied as the sociocultural practices in which we are engaged into as human beings.

The concept of affordance has also been discussed in the fields of social sciences, human geography and anthropology, in relation to the actor network theory and practice theory (Bærenholdt 2012; Rantala, Valtonen, and Markuksela 2011). Especially Ingold (2000) has developed Gibson's concept of affordance with a phenomenological approach that has been influential in the later applications of the concept. According to Ingold $(2000,168)$, Gibson assumed that the perceiver moves around a world that is somehow pre-pared with all its affordances ready. Ingold 
highlights that from the phenomenological standpoint "the world emerges with its properties alongside the emergence of the perceiver in person, against the background of involved activity" (Ingold 2000, 168). For example, in their study of curious play, Gurholt and Sanderud (2016) analyze children as discovering themselves in relation to their surrounding through dwelling the landscape and through being active participants in their own life-world. Accordingly, Bærenholdt (2012) believes that the strength of the concept of affordance stems from the possibility of a sensuous and bodily research approach. By applying a relational, sensuous approach, we can address the role of enskilment ('the embodiment of capacities of awareness and response by environmentally situated agents' - Ingold 2000, 5), customary knowledge, and dynamic engagement that take place when affordances are perceived (Ingold 2011, 11-12).

The relational approach to affordances highlights the dynamic interaction, appreciates children as active beings, and recognizes their attentiveness to their surrounding non-human world (Rautio 2013). Hence, the dynamic perspective focuses on the simultaneous emergence of the perceiver, the perception of the affordance, and the affordance itself. Attention is paid to the relational aspects of the process of perceiving the affordances, such as the role of enskilment, abilities and motivations (Rietveld and Kiverstein 2014) and the role of pre-reflexive bodily sensing that is highlighted in children's relationships with their surroundings (Gurholt and Sanderud 2016). Laaksoharju's and Rappe's (2017) examination of experience-based learning with trees illustrated that engagement with trees motivated children to increase their creativity and their handling of the possible tree-related risks on their own. The availability of affordances in the environment and the social interplay were very much interconnected and seemed to support each other. Similarly, by applying a hermeneutical-phenomenological approach, Skar, Gundersen, and O’Brien (2016) were 
able to see children's nature contact as a relational interaction, children and nature as interacting agents, and the human-nature relationship as a dynamic and emotional relation rather than an object and subject relation.

Here, we apply a relational approach to affordances in order to pay attention to how relationships between young people, children and families and their surroundings are formed in processes of mundane living (Rautio 2013) that take part in outdoor living context.

\section{Materials and methods}

We use two data sets to analyze how children, young people and families interact with nature during outdoor recreation and how the interaction affects their well-being. Our secondary data originates from our two studies that were not originally gathered to study affordances and well-being (XXX 2014; XXX 2014; XXX 2019 masked for blind review). When analyzing engagement with nature in these studies and discussing the findings together, we became aware of the aspects related to well-being in data cases and wanted to analyze these insights further. The different quality of the data sets thematic writings and an ethnographic data - seemed to supplement each other. Therefore, this paper combines two data sets in order to tease out the dynamic emergence of well-being issues when analyzing engagement with nature. Our study is an example of amplified analysis in which 'researchers who separately conducted independent studies later performed an analysis of the two data sets to further explore common and/or divergent issues across two study populations' (Heaton 2004, 47). We followed the guidelines for assessing the re-usability of qualitative data sets and took into consideration quality and suitability of our previous data sets (Heaton 2004, 92; Hinds et al. 1997). 
First case consists of thematic writings of 15-21-year-olds living in the city of Lahti with over 100000 inhabitants and in the surrounding area in southern Finland. The young people were asked to answer open-ended, thematic questions and one structured question about their frequency of participation in 21 outdoor activities during summer and 11 activities during winter (i.e. 'How often do you participate in the following activities during summertime/wintertime? Please circle the alternative that best describes your participation'). Respondents' sex, year of birth, municipality of residence, and house type were also enquired. The thematic questions covered five broad themes: 1) leisure time and favorite places, 2) perception of nature, 3) leisure time in natural environments and motives for spending/not spending time in nature, 4) most preferred natural environments and elements, and 5) nature-related skills and knowledge learned from previous generations. Moreover, the young people were asked to write or draw their most precious memory of nature (drawings not included in this paper). The length of the responses to each theme varied from one word to over half a page written by hand. The data was collected in 2013 from pupils of two schools: a Rudolf Steiner school and a vocational school. The respondents $(\mathrm{N}=184)$ were born between 1992 and 1998 , and over two thirds (69\%) of them were female.

In order to gain deeper access to relational engagement with affordances and the dynamic emergence of the participants, nature and well-being, we use a secondary data from a research project that focused on practices of sleeping outdoors. A larger ethnographic data was collected, of which those parts that included families and young people were reanalyzed for the study at hand. This data consists of the first author's autoethnographic field notes from camping with her family in northern Finland and northern Norway in summer 2011 and 2015, participant observations from visiting 27 
young scouts camping in snow caves in northern Finland in spring 2012, and a focus group discussion with four camping mothers in northern Finland, in spring 2012.

The participant observations with the scouts were produced both during the meetings before the camp and during the camp - by the first author visiting the camp for 24 hours, engaging in the activities with scouts, through informal discussion, and by sleeping in a tent next to the camp. The focus group discussion focused on practices of the mothers who camp often with their family. By camping, we refer to overnight stays in simplified outdoor settings - either along hiking or skiing routes, in forests and fells, or sleeping in a tent alongside a road. The ethnographic data captures the various practices of young people and families spending time in nature with rhythms of being outdoors. Within analytical ethnographic paradigm, the core idea is that the researcher is a full member in the research group or setting, conducts critical reflexivity throughout the research process - when producing the data, when analyzing it, and when producing thick description in the form of research articles and reports - and is committed to developing theoretical understandings of a broader social phenomena (Anderson 2006; Foley 2002). The data production and the analytical interpretation of the ethnographic data is seen as an intertwined process, where the corporeal and sensual encountering of the life-world forms a central part of the researcher's knowledge production process (Vannini 2015).

We analyzed the data by applying the relational approach - that is, by paying attention to the dynamics of encountering nature and to the interplay between young people and the environment and between families and the environment. We interpreted our data collectively in order to avoid missing any relevant contextual information or epistemological viewpoints related to the original research contexts that could lead to misinterpretation of the data (see van den Berg 2005 and Moore 2007 on the reuse of 
data), and to reflect continuously on the interplay between our relational approach and the insights arising from the empirical data. The analysis focused on the perception of the affordances, and on the simultaneous emergence of the affordance and the perceiver itself. The analysis process can be seen as a process of (re)constructing the data (Hammersley 2010) with the help of the relational approach, in which case applying information from the original research context is relevant, especially since the role of the researcher is thoroughly intertwined in the analytical, autoethnographic ethnographic research process. This is also relevant in our case where we focused on the relational processes of emergence.

Based on our collective interpretation, we next introduce (1) affordances related to outdoor recreation that affect well-being, and then discuss the relational process of emergence by focusing on both (2) the materiality of the environment in which the outdoor recreation takes place and on (3) the enskilment of the young people, children and families on perceiving the affordances related to well-being. The affordance approach has been critiqued for not being able to bring the material agency itself into the studies (see Merewether 2019, 107). In our analysis process, the intention was to pay particular attention to the emergence of the material environment in the dynamic process, but we acknowledge the analysis process being more human-centric.

\section{Affordances related to outdoor recreation}

\section{Thematic writings}

Nature affords various activities for young people, as indicated by the responses to the structured question about participation in outdoor recreation. In summertime, the most popular activities were sunbathing and spending time at the lakeside or in nature, and swimming in natural waters; over half of the young respondents participated in these 
activities weekly. Furthermore, approximately $40 \%$ of the respondents visited cottages in the countryside or boated monthly. During wintertime, the participation rates were considerably lower; around a fifth of the respondents visited cottage or photographed nature monthly. The thematic writings provided further information on outdoor recreation. The most common activities, mentioned by almost two thirds, were walking, jogging and spending time in nature. Almost $40 \%$ of the young respondents considered nature important, while nature was only somewhat important for half of them, and not at all important for a tenth. Those who considered nature important participated in more outdoor activities than the others. However, some people considered nature important although they did not participate in special outdoor activities.

I do not like to spend time in nature because there is nothing to do in the forest and it is more unsafe in places in which there are not many people. --- In spring it is lovely to listen to birdsong and the sound of gurgling water. I also like to watch little birds. Apple trees are important because in summer I swing in the yard, and in autumn you can eat the apples. (Thematic writing 4 , female, 15 years old)

When asked the motives for spending time in nature, young people more often mentioned emotional engagement with nature and psychological benefits than physical activities. Young people spent time in nature because it, for instance, afforded relaxation, restoration, increased energy and improved concentration, which have been identified as important aspects of well-being.

Exercising and especially exercising outdoors is quite important for me because you can stay in peace outdoors and it is easier to think about issues. Concentrating on things is sometimes extremely difficult and that is why I usually go outdoors before reading to exam. (Thematic writing 63, female, 16 years old) 
Nature also helped increase young people's self-esteem and improve hope about tomorrow. These kinds of emotional and psychological benefits may have wide-ranging positive effects on young people's everyday life.

My relationship with nature has improved lately. It has become quite an important part of my life. It helps me cope with my minor illness and to believe in the future. I have really learned to enjoy it during the last year. It has given me the chance to think about values and my own characteristics. Now I appreciate myself more. (Thematic writing 56, female, 16 years old)

The thematic writings indicated young people's need for both places of social interaction during leisure and places of retreat, where it is possible to avoid other people. When the respondents wrote about their leisure time in general, two thirds of them mentioned friends, over a tenth family members or a girl/boyfriend, and only a few wrote that they spend leisure time alone. However, when the respondents described their time spent in natural environments, less than a tenth wrote about friends or family members.
I spend time in nature at our summer cottage. I think the cottage environment has to be peaceful and far away from everything 'city', and no neighbors should be close by. When I was hiking, I liked 'the wilderness life' when you did not really have to think about anything and you could look as you wanted. I like to be in nature and outdoors, when I only have time. It refreshes me and I sleep better. If you stay only inside, you feel tired all the time. (Thematic writing 164, female, 19 years old)

\section{Ethnographic data}

The ethnographic data related to camping and sleeping outdoors formed a context which highlighted the activities related to spending longer times in nature - such as scout camps, sleeping in a tent or open hut, and hiking and skiing trips. These activities enable learning skills in handling equipment related to outdoor life, learning about 
seasonal rhythms and different weather conditions, and learning how these affect living outdoors. The mothers in the focus group discussion and the instructor from the scout camp talked about being involved in basic activities: making food and preparing camp, washing dishes and spending time with friends and family.

Mother 1: It is about basic activities. One does not need to overload the brain all the time. (Laughs) It is just great. It is exactly about washing dishes with snow, as you (Mother 2) described, and other things that are psychically easy. It is great when you can just perform those activities.

Mother 2: Yes, I think it is in a way Finnish meditation, being in nature. There is no extra work for your brain, you can clean what you have there or just be without thinking.

Mother 3: Yes, exactly. There is not too many stimulus. And probably that is one reason why one sleeps well in nature. (Focus group discussion)

Outdoor life affords families' and young people's engagement in basic everyday activities at a slower rhythm than that in the daily environment, as well as learning how to carry out these activities in an outdoor environment. This furthermore enables intensive engagement with both one's companions and the environment.

Intensive engagement with family or with one's group afforded by camping life was illustrated in many ways. Scouts described how they learn how others like to fall asleep in a snow cave: one friend wants to turn around many times in the sleeping bag, another likes silence. One of the mothers said that when spending time in a tent, children seem to be at the center - they get attention more easily. Hence, getting away from work, normal routines and everyday worries enables relaxation, restoration and strengthens bonds within families, at the same time also improving motivation for everyday life. 
Nature also affords sleeping the whole night - the first author noted several times in her autoethnographic field notes that the children slept much better in the tent.

Kids love being out. They were happy to have few days in cabin, but when we are camping in the wild, they do not stop playing the whole evening. They have some difficulty in calming down in the tent - it is so tempting to roll around, but once they fall asleep they really sleep!!! (This they do not do very often at home - sleeping a whole night without waking up.) (Field notes, Camping trip 2015)

In the everyday life of a family with small children, getting enough sleep can become a central issue in terms of well-being. Similarly, the camping mothers described how nature affords calming down in the evening; a few families had transferred this to their everyday home life and had candles or fewer lights in the evening to calm the children before going to sleep. Staying overnight in nature seems to enhance the well-being of families by enabling them to pay attention to the rhythms of sleep and to issues that make it possible to adjust life to the family's own rhythms.

Finally, we find a nice place away from the road a bit, along a smaller bumpy road. Not a perfect spot, but good in this kind of sunny weather. No other people, a waterfall, a clean eating place, and a place to make a fire. The kids like it here when there is space around - since they can play without needing to hear too many warnings and 'don'ts': don't step on the tent, don't throw things there, and don't ride your bike there. Also, I like it when I don't need to be worried that our noise is bothering other people. (Field notes, Camping trip 2015)

Generally, outdoor living affords having less things around, which may result in children using their imagination and materials from nature when playing. It affords young people to sleep late in the dark, silent snow cave, with no computers and phones available all the time. According to the instructor of the scout camp, one of the most important reasons for organizing the camp is "to get the young ones away from computers to experience other kind of life". Having less things enables families and 
young people to organize things with a rhythm that is 'natural' to them, or with a rhythm that fits the 'form of life' (Rietveld and Kiverstein 2014) that they are currently living.

\section{Encountering nature}

\section{Thematic writings}

The material properties of the natural world support diverse affordances and enable enhancing well-being. According to the thematic writings, the most preferred natural environments were the forest and lakesides, but the young people also mentioned other places such as the surroundings of the summer cottage, water areas and parks. Over a quarter of the respondents wrote about their favorite places. Almost half of them told that their favorite place was located in nature, the shore of a lake for instance, or a hill in the forest, or a rock by a lake.

Due to everyman's right, natural environment can be quite easily encountered near the home even in more densely populated southern Finland. Nature located close to the young respondents' homes was most often the forest, but other environments such as water areas and lakesides, yards, jogging/skiing tracks and parks were also mentioned. Only less than a tenth of the respondents wrote that there was not (enough) accessible nature close to their homes. Of natural areas visited farther away from home, a summer cottage and its surroundings were most often mentioned. Certain nature areas afford diverse activities - for instance, a lakeside affords sunbathing and swimming but even the smallest, or invisible properties of nature may play an important role in enabling the encountering of affordances. Environmental features may signify a connection between people and nature, and according to O'Brien, Morris, and Stewart 
(2014), this awareness and experience is beneficial in terms of perceived health and well-being.

\begin{abstract}
Nature is important to me, and it's nice to run or walk in the forest, to look at small pink twinflowers, to listen to birdsong and to embrace spruces which rise majestically towards the sky. There is so much life around me in nature, which does not attack you, so I think it is very precious. Because nature is a reflection of another world, and in nature this 'secret world', with its invisible parts, is close to humans. (Thematic writing 72 , female, 18 years old)
\end{abstract}

The thematic writings indicated that well-being is often related to affordances that enable pleasant sensations and embodied experiences such as listening to silence or the sounds of nature, breathing in fresh air, smelling or feeling nature, or enjoying visually beautiful scenery.

In the backyard, it is nice to sit in the rocking chair and look at the apple tree just burst into bloom and the flowers planted by mom. Sometimes the neighbor's black cat sits on my lap and sleeps there. A nice place. Birdsong is priceless. Our little apple tree looks beautiful. When water is beating against the shore at the cottage, nothing beats it. (Thematic writing 95, male, 19 years old)

Environmental features may also restrict perceiving affordances related to well-being. When asked about motives for spending/not spending time in nature, less than $15 \%$ of the young respondents wrote about the negative aspects of nature such as insects/bugs, weather conditions, snakes or allergens. The restrictive role of climatic conditions was also illustrated by lower participation rates in outdoor recreation in winter. The other restrictive features attached to natural environments were dangers caused by other people (e.g. rapes), boredom and lack of interest.

I do not spend much time in nature during leisure time. I do not feel it is necessary to go and stand alone or in company in the forest, and mountain biking or picking mushrooms or berries is not for me. (Thematic writing 58, male, 16 years old) 


\title{
Ethnographic data
}

In the ethnographic data the role of weather and seasons was apparent in relation to when to go camping and what was done while camping. For example, camping trips with small children were planned at times when there would not be so many mosquitoes and when it would not yet be very cold. The participants at the scout camp also vividly described what it means to camp in a cold environment: you wake up in the night and it is cold, all your clothes are cold when you need to change, and even your candies are cold. The coldness affords campers to appreciate the easiness of everyday life but does not seem to prevent them from returning - many scouts had participated in the same snow cave camp in previous years. However, support gained from more experienced scouts was important for perceiving diverse affordances.
The instructor from the scout camp tells me that the hard work related to digging the caves affords the younger ones to test their limits. They have informed the parents that the trip will be intense and harsh but that the participants will get help when they meet their limits. This help is not offered straight away, but after the 'first crying'. (Field notes, Scout camp)

\begin{abstract}
After the first day at scout camp, many of the young people were very tired and a bit hungry when they went to bed. They had felt cold and had not slept well. This is something that the mothers also discussed in their focus group - outdoor living teaches people to estimate the impact of weather and outdoor conditions on their practices. In cold or rainy weather, things might take longer than in sunny weather. In cold weather, one needs to carry out practices in a more effective way.
\end{abstract}

\footnotetext{
Mother 4: I have been thinking about this - how much more people would get out of their experiences in nature if different perceptions on time were brought up - different time than clock-time. Those who are experienced in acting in nature know that two hours can mean very different things depending on the conditions of that moment. Depending on amount of day light, on season... (Focus group discussion)
} 
Learning how to carry out practices in different kinds of seasonal and weather conditions - or in specific places, enables diversification of the ways how nature is encountered, which furthermore affects the perception of affordances related to gaining well-being.

\section{Dynamic engagement with nature}

\section{Thematic writings}

From the perspective of enskilment, abilities and motivations, social interaction within families plays an important role in the perception of affordances. Over $70 \%$ of the young respondents who engaged in outdoor recreation and considered nature important, had learned nature-related skills and knowledge from their close ones, mainly from parents and grandparents. Of those who did not consider nature important, less than half had learned nature-related skills and knowledge from previous generations. Young people had been engaged in how to become active participants in surrounding outdoors when time was spent together in a natural environment - often at a summer cottage. Older generations had engaged young people in skills and knowledge related to, for instance, hiking and surviving in the wilderness, fishing, hunting, boating, berry and mushroom picking, forest work and gardening, but also in the recognition of species, appreciation of nature, and rules of how to behave in nature. When young people grow older, they continue learning and developing these outdoor skills, which may have a wide-ranging effect on their everyday life (e.g. career choice) and further affect their ability and enskilment to perceive diverse affordances.

Since I was a kid I have been taught to respect nature and appreciate its beauty. I have been taken fishing, berry picking, and mushroom picking. I have learned to recognize fish, berry, and mushroom species. Maybe that's why I have become interested in food? (Thematic writing 84 , male, 19 years old) 
Moreover, parents or grandparents engage young people in perceiving affordances by telling stories about natural environments. Previous generations were also mentioned in the writings about the most precious nature memories; the young people described time spent together with grandparents or parents in childhood. These memories highlighted that being outdoors in nature increased well-being through pleasant and satisfactory sensations; embodied experiences of nature are memorable.

\begin{abstract}
When I was a child, I used to spend a night at my grandmother's summer cottage with my brother at least once a summer. We went fishing along the stream and swimming in the pond. I also remember that we picked wild strawberries near the cottage and ate them with vanilla ice cream. This is one of my most precious nature memories. (Thematic writing 159, female, 19 years old)
\end{abstract}

\title{
Ethnographic data
}

The emergence of the perceiver in person was illustrated in the ethnographic data especially when the growth and development of skills of the children and young people was articulated - either by their parents and companions or in the form of shared memories (the growth was also evident because the first author had field notes from time when her first child was born and from time when the child was four year old). It is evident that young people and children are in the process of emergence as perceivers. For example, the development of skills was visualized when discussing the distances or the affordances that children perceive at each age. A baby was described as lying in a tent, wondering at the red color filtered through the fabric, whereas four-year old rolled around the tent in woolen underwear enjoying the soft, safe world. Children were first carried in the back carrier, then walked or skied small distances, and later carried their own backpacks. Thus, nature affords perceiving the dynamics that take place within the family as children grow up. 
The dynamic process was also illustrated when mothers discussed how learning to dress their children in accordance with the weather conditions, or learning what kind of trip fits each stage of life, enables them to enjoy their time in nature. Learning from experience enabled them to perceive more affordances that affect well-being. The instructors in the scout camp also recounted how young campers are first allowed to try things themselves, and when they have met their limit, they receive help. Thus, the human - nature encounter forms a dynamic process because the person changes when learning new skills and developing more strengths (or when dressing better), and because the conditions in nature change.

Furthermore, the data illustrated that it takes some time to get into the rhythm of nature and this affects how nature is encountered. It takes a few days to leave the everyday hustle and bustle behind and get into the tempo of living outdoors.

\begin{abstract}
After the evening snack and warm drink, we had a nice evening walk at the beach, and now we are finally in the tent. We are still getting into the mood of moving and being in the open air, not there yet. (Field notes, Camping trip 2015)
\end{abstract}

The dynamic process of 'being-in-the-world' becomes visible in the feelings experienced during camping - both relaxed, frustrating and scary moments are experienced. Accepting the dynamics that atmospheres change quickly due to hunger, tiredness, weather and mosquitos is one part of outdoor living and dynamic engagement with affordances. It takes some time to get accustomed to this. However, when the dynamics are accepted, these observations can be used in everyday environments to enhance well-being by, for example, becoming aware of hunger or tiredness more easily or by accepting the changes in atmospheres and realizing how one can affect these changes.

\title{
Discussion
}


Our findings showed that young people, children and families engage with recreational environments in diverse ways that affect their well-being. Most young people emphasize the importance of nature; natural environments enable various activities and meeting up with friends, but also support retreat behaviors by affording privacy, freedom from the pressures of friends and everyday life, and calming down and enjoying oneself (see Kyttä 2003; O’Brien, Morris, and Stewart 2014; Laaksoharju and Rappe 2017). Our data also suggested that spending time with family in natural environment is valued. When engaging longer times with nature, young people, children and families are able to spend intensive time together and to conduct daily practices in different rhythm than in an everyday life. Outdoor recreation seems to enable young people and families to perceive possibilities to do things differently and gives them space for expressing different emotions and for developing diverse skills. It is this possibility, or extra space, that especially affects their well-being. Earlier studies (e.g. Gurholt and Sanderud 2016) have also highlighted that children are active participants in their life-words and that engagement with the surrounding natural environment is a dynamic process. However, in order to support engagement with nature and an active relationship to develop, time and places for encounters are needed.

Rautio (2013) has invited children's geographers to become more aware of the diversity of ways in which children engage with nature and are part of it. She points out that children apply an openness towards their material surroundings. Our findings showed that this kind of openness needs to be practiced and recognized - children and young people become skilled in engaging with the natural environment through practice and through perceiving possibilities for engagement.

Both individual families and society can support engagement with nature and gaining well-being benefits. Our findings showed that the role of free time spent 
together with the family in nature areas is very important for the perception of affordances. For example at summer cottages or camping trips, nature-related skills are practiced and knowledge produced together by different generations, and children and young people may become active participants in their own life-worlds. However, the role of school and daycare centres has been recently highlighted due to unequal opportunities of families to ensure engagement with nature. In Finland, children and youth are supported to engage with nature in diverse ways, for instance by organizing forest trips and teaching outdoor activities such as orienteering and cross-country skiing at school. However, innovative nature-based activities, events and campaigns should be developed for young people and their wide-scale participation in various hobbies supported. Outdoor courses or family clubs could support learning outdoor skills and encouraging families to spend time in natural environment also on their own.

Interaction within families affects individual urges and capabilities, but the perception of affordances also depends on situational and physical circumstances. Our findings showed significantly lower rates of participation in outdoor activities during the winter among the young people living in southern Finland, where snow-and icedeficient winters have increased. At the same time, the camping mothers living in northern Finland often mentioned winter activities. In Finland, climatic conditions have traditionally afforded different kinds of outdoor activities during snowy wintertime compared to summer. However, lack of snow or ice coverage on water areas, cold or wet weather, darkness or slippery conditions may restrict perceiving affordances. The absence of snow affects not only sport activities such as cross-country skiing but also the tradition of playing with and building from snow.

It would be worth investigating more closely how the changing seasonal conditions affect the availability of affordances related to being outdoors and learning to 
perceive new affordances - becoming skilled in acting in the changed seasonal conditions. Hence, climate change and its impacts on physical circumstances are crucial from the perspective of outdoor recreation (Nicholls 2006). The impacts of climate change may be mitigated by using adaptation strategies such as making artificial snow in skiing centers, but these kinds of strategies may have no effect on the possibilities for daily outdoor activities near young people's homes. Instead, paying more attention to learning to adapt one's practices to diverse seasonal conditions might be more beneficial (see Hitchings 2011b). For instance in flexibly organized sports activities, the timing is not fixed beforehand, but children's activities are determined on the basis of the seasonal conditions and weather. In fact, some recent forms of outdoor recreation that are suitable for various climatic conditions (e.g. fatbiking, geocaching) have increased their popularity.

In regard to the places for encounters, our findings showed that forest and lakeside areas were the most preferred natural environments for the young people. In our ethnographic data, the benefits of spending longer times in simplified outdoor settings were illustrated by, for instance, improved ability to perceive both the rhythms of nature, personal rhythms and the dynamics between these, which gradually expanded after staying outdoors for a few days. The findings suggest that it is important to not only build urban parks and playgrounds but also to preserve more natural environments that attract children to play and spend unstructured time with their families. These areas close to population centers would support the dynamic relationships between youth, children and natural environments and becoming skilled in diverse outdoor environments and eager to visit also the remote natural areas. Natural environments have been found to differ in their restorative potential (Han 2010; Puhakka, Pitkänen, 
and Siikamäki 2017). In Finland, there are public transport connections to many national parks, and easy accessibility should be further promoted.

The human-nature interactions as relational and dynamic emergences were illustrated in our ethnographic data, for example, in relation to getting to know the impacts of various weather conditions and observing the development of personal skills related to staying outdoors for longer times (see Ridgers, Knowles, and Sayers 2012). Once families learn, for example, to equip themselves according to the weather, the possibilities related to using the outdoors to gain well-being benefits expand. These findings draw upon Laaksoharju's and Rappe's (2017) result that the use of affordances deepens and becomes multifaceted after getting to know a place, yielding connectedness to a place and finally connectedness to nature. Planning biodiverse, low-maintenance spaces is recommended, as these will invite children to use green spaces according to their needs.

Skar, Gundersen, and O’Brien (2016) highlight the role of free, spontaneous play as a key to more bodily, emotional and sensuous interaction with nature. In their study, parents often chose structured outdoor activities and organized events instead of unorganized family trips, due to easiness and limited time resources. Similarly, our findings suggest that perceiving possibilities for families and young people to stay outdoors is a relational process that is intertwined with processes of enskilment and emergence - and require allowing child-directed, place-based play in nature areas (see Laaksoharju and Rappe 2017). Enskilment and emergence are not only related to the cognitive abilities gained when spending time in nature; they are also associated with the dynamics-related ability to perceive possibilities for emotional engagement.

Limitations of this study are related to the secondary data sets: two very different data sets were combined for the analysis since they were seen to complement each 
other. As the data sets were originally produced for other purposes and in two different regions in Finland, the analysis remains little fragmented. However, there have been recent calls for researchers to engage with "messy" research processes and produce, use and reuse, and analyze the research data in creative ways - also in children's geographies (Moore 2007; Rautio 2013). For future research, we recommend producing creatively data that especially focuses on how children and youth in different areas get access to the time and places needed for engaging in the processes of emergence with nature.

\section{Conclusion}

By applying the relational approach and the concept of affordance, this study indicated that engagement with nature enables young people to calm down and to get away from the pressures of everyday life and affords close interaction for families and possibilities to do things differently. The relational approach makes visible that the more children, young people and families spend time in nature, the more they are able to perceive affordances that enhance their well-being. In order for a dynamic relationship to develop, time and places for encountering nature are needed - especially since time spent in nature as a child seems to affect how affordances are perceived in teenage and adulthood. In the future, more emphasis should put on how to support families to engage with natural environments. Along the development of urban parks, "safe training environments" - such as summer cottages in Finland - should be secured more widely. Time and places for engagement with nature should be available throughout the yearin different seasons and weather conditions, in order for children and young people to be able to adapt their practices and learn to spend time in diverse seasonal conditions. The relational approach illustrates the role of these dynamic aspects well. For instance, the role of availability and accessibility of natural environments and knowledge of how 
to use the environment are related to each other and vary due to both seasonal changes in nature and changes in family dynamics. Rather than seeing young people's and families' relations with nature as subject-object relations, we need to be more aware of the diverse ways in which we relate with nature already.

\section{References}

Anderson, L. 2006. “Analytic Autoethnography.” Journal of Contemporary Ethnography 35(4), 373-395. doi: 10.1177/0891241605280449

Brymer, E., K. Davids, and L. Mallabon. 2014. "Understanding the Psychological Health and Well-Being Benefits of Physical Activity in Nature: An Ecological Dynamics Analysis.” Ecopsychology 6: 189-197. doi:10.1089/eco.2013.0110

Bærenholdt, O. J. 2012. “Enacting Destinations. The Politics of Absence and Presence.” In Actor-network theory and tourism. Ordering, materiality and multiplicity, edited by G. T. Jóhannesson, C. Ren, and R. van der Duim, 111-127. London: Routledge.

Cameron-Faulkner, T., J. Melville, and M. Gattis. 2018. "Responding to Nature: Natural Environments Improve Parent-Child Communication.” Journal of Environmental Psychology 59, 9-15. doi:10.1016/j.jenvp.2018.08.008

Dinnie, E., K. M. Brown, and S. Morris. 2013. "Community, Cooperation and Conflict; Negotiating the Social Well-Being Benefits of Urban Greenscape Experiences.” Landscape and Urban Planning 112: 1-9. doi: 10.1016/j.landurbplan.2012.12.012 Foley, D. 2002. “Critical Ethnography: The Reflexive Turn.” International Journal of Qualitative Studies in Education 15(4), 469-490. doi: $10.1080 / 09518390210145534$ 
Fuller, R. A., K. N. Irvine, P. Devine-Wright, P. H. Warren, and K. J. Gaston. 2007. "Psychological Benefits of Greenspace Increase with Biodiversity.” Biology Letters 3: 390-394. doi:10.1098/rsbl.2007.0149

Gibson, J. 1979. The Ecological Approach to Visual Perception. Boston: Houghton Mifflin.

Gibson, J. 1994[1977]. “Teoria tarjoumista [The theory of affordances]." Psykologia 3: appendix, 14-24.

Gurholt, K. P., and J. R. Sanderud. 2016. “Curious Play: Children's Exploration of Nature." Journal of Adventure Education and Outdoor Learning 16: 318-329.

Hammersley, M. 2010. “Can We Re-Use Qualitative Data Via Secondary Analysis? Notes on Some Terminological and Substantive Issues." Sociological Research Online 15(1): 5. doi:10.5153/sro.2076

Han, K. 2010. “An Exploration or Relationships among the Responses to Natural Scenes: Scenic Beauty, Preference and Restoration.” Environment and Behavior 42: 243-270. doi:10.1177/0013916509333875

Hanski, I., L. von Hertzen, N. Fyhrquist, K. Koskinen, K. Torppa, T. Laatikainen, P. Karisola et al. 2012. "Environmental Biodiversity, Human Microbiota, and Allergy Are Interrelated.” PNAS 109: 8334-8339. doi:10.1073/pnas.1205624109

Hartig, T., M. Mang, and G. W. Evans. 1991. "Restorative Effects of Natural Environment Experiences." Environment \& Behavior 23: 3-26. doi:10.1177/0013916591231001

Heaton, J. 2004. Reworking Qualitative Data. London: SAGE Publications. Hinds, P. S., R. J. Vogel, and L. Clarke-Steffen. 1997. "The possibilities and pitfalls of doing a secondary analysis of a qualitative data set." Qualitative Health Research 7: 408-24. doi:10.1177/104973239700700306 
Hitchings, R. 2011a. "Researching Air-Conditioning Addiction and Ways of Puncturing Practice: Professional Office Workers and the Decision to Go Outside." Environment and Planning A 43: 2838-2856. doi:10.1068/a43574

Hitchings, R. 2011b. “Coping with the Immediate Experience of Climate: Regional Variations and Indoor Trajectories." WIREs Climate Change 2: 170-184. doi:10.1002/wcc. 106

Ingold, T. 2000. The Perception of the Environment. Essays on Livelihood, Dwelling and Skill. London: Routledge.

Ingold, T. 2011. Being Alive. Essays on Movement, Knowledge and Description. London: Routledge.

Kabisch, N., M. van den Bosch, and R. Lafortezza, R. 2017. “The Health Benefits of Nature-Based Solutions to Urbanization Challenges for Children and the Elderly A Systematic Review.” Environmental Research 159: 362-373. doi:10.1016/j.envres.2017.08.004

Kaczynski, A. T., and K. A. Henderson. 2007. "Environmental Correlates of Physical Activity: A Review of Evidence about Parks and Recreation.” Leisure Sciences 29: 315-354. doi: 10.1080/01490400701394865

Kaplan, R. 2001. "The Nature of the View from Home.” Environment and Behavior 33: 507-542. doi:10.1177/00139160121973115

Keniger, L., K. Gaston, K. N. Irvine, and R. Fuller. 2013. "What Are the Benefits of Interacting with Nature?" International Journal of Environmental Research and Public Health 10: 913-935. doi:10.3390/ijerph10030913

Kuo, F. E., and W. C. Sullivan. 2001. "Aggression and Violence in the Inner City. Effects of Environment via Mental Fatigue.” Environment and Behavior 33: 543 571. doi:10.1177/00139160121973124 
Kuo, F. E., and A. Faber Taylor. 2004. "A Potential Natural Treatment for AttentionDeficit/Hyperactivity Disorder: Evidence from a National Study.” American Journal of Public Health 94: 1580-6.

Kyttä, M. 2003. “Children in Outdoor Contexts. Affordances and Independent Mobility in the Assessment of Environmental Child Friendliness." Helsinki University of Technology, Centre for Urban and Regional Studies A 28.

Laaksoharju, T., and E. Rappe. 2017. “Trees as Affordances for Connectedness to Place - A Framework to Facilitate Children's Relationship with Nature.” Urban Forestry \& Urban Greening 28: 150-159. doi:10.1016/j.ufug.2017.10.004

Laaksoharju, T., E. Rappe, and T. Kaivola. 2012. “Garden Affordances for Social Learning, Play, and for Building Nature-Child Relationship." Urban Forestry \& Urban Greening 11: 195-203. doi:10.1016/j.ufug.2012.01.003

Lindhagen, A., and L. Hörnsten. 2000. "Forest Recreation in 1977 and 1997 in Sweden: Changes in Public Preferences and Behaviour." Forestry 73: 143-153. doi:10.1093/forestry/73.2.143

LUKE. 2010. “Outdoor recreation statistics.” LUKE. Accessed April 252018. http://www.metla.fi/metinfo/monikaytto/lvvi/tilastot_2010/2010-taulukko-1.htm Maller, C. J. 2009. “Promoting Children's Mental, Emotional and Social Health through Contact with Nature: A Model." Health Education 109: 522-543. doi:10.1108/09654280911001185

Merewether, J. 2019. “New Materialisms and Children’s Outdoor Environments: Murmurative Diffractions.” Children's Geographies 17: 105-117. doi:10.1080/14733285.2018.1471449

Moore, N. 2007. “(Re)Using Qualitative Data?” Sociological Research Online 12:1. doi:10.5153/sro. 1496 
Muirhead, S. 2011. Health, Well-Being and Engagement with Landscape: A Literature Review. SAC, Edinburgh. http://www.socialfarmingacrossborders.org/images/custom/uploads/40/files/Healt h\%20and\%20wellbeing.pdf

Nicholls, S. 2006. "Climate Change, Tourism and Outdoor Recreation in Europe." Managing Leisure 11: 151-163. doi:10.1080/13606710600715226

O’Brien, L., J. Morris, and A. Stewart. 2014. “Engaging with Peri-Urban Woodlands in England: The Contribution to People's Health and WellBeing and Implications for Future Management.” International Journal of Environmental Research and Public Health 11: 6171-6192. doi:10.3390/ijerph110606171

Puhakka, R., K. Pitkänen, and P. Siikamäki. 2017. "Health and Well-Being Impacts of Protected Areas in Finland.” Journal of Sustainable Tourism 25: 1830-1847. doi:10.1080/09669582.2016.1243696

Rantala, O., A. Valtonen, and V. Markuksela. 2011. "Materializing Tourist Weather: Ethnography on Weather-Wise Wilderness Guiding Practices.” Journal of Material Culture 16: 285-300. doi:10.1177/1359183511413646

Rautio, P. 2013. "Children who carry stones in their pockets: on autotelic material practices in everyday life." Children's Geographies 11: 394-408. doi:10.1080/14733285.2013.812278

Rietveld, E., and J. Kiverstein. 2014. “A Rich Landscape of Affordances.” Ecological Psychology 26: 325-352. doi:10.1080/10407413.2014.958035

Ridgers, N. D., Z. R. Knowles, and J. Sayers. 2012. “Encouraging Play in the Natural Environment: A Child-Focuses Case-Study of Forest School." Children's Geographies 10: 49-65. doi:10.1080/14733285.2011.638176 
Sievänen, T., E. Pouta, and M. Neuvonen. 2007. "Recreational Home Users - Potential Clients for Countryside Tourism?" Scandinavian Journal of Hospitality and Tourism 7: 223-242. doi:10.1080/15022250701300207

Skar, M., and E. Krogh. 2009. “Changes in Children’s Nature-Based Experiences near Home: From Spontaneous Play to Adult-Controlled, Planned and Organised Activities." Children's Geographies 7: 339-354.

doi:10.1080/14733280903024506

Skar, M., V. Gundersen, and L. O’Brien. 2016. "How to Engage Children with Nature: Why Not Just Let Them Play?" Children's Geographies 14: 527-540. doi:10.1080/14733285.2015.1136734

Tyrväinen, L., A. Ojala, K. Korpela, T. Lanki, Y. Tsunetsugu, and T. Kagawa. 2014. “The Influence of Urban Green Environments on Stress Relief Measures: A Field Experiment." Journal of Environmental Psychology 38: 1-9.

doi:10.1016/j.jenvp.2013.12.005

van den Berg, A. E., S. L. Koole, and N. Y. van der Wulp. 2003. "Environmental Preference and Restoration: (How) Are They Related?" Journal of Environmental Psychology 23: 135-146. doi:10.1016/S0272-4944(02)00111-1

van den Berg, H. 2005. "Reanalyzing Qualitative Interviews from Different Angles:

The Risk of Decontextualization and Other Problems of Sharing Qualitative Data.” FQS Forum: Qualitative Social Research 6(1), Art. 30.

Vannini, P. 2015. "Non-representational ethnography: new ways of animating lifeworlds." Cultural Geographies 22: 317-327. doi: 10.1177/1474474014555657 